\title{
Concealed AV junctional extrasystoles simulating second-degree sinoatrial block
}

\author{
A. Brat \\ From the Department of Clinical Medicine, Cardiology Centre, University of Florence, Florence, Italy
}

Concealed $A V$ junctional extrasystoles are described which, conducted in a retrograde manner to the sinoatrial junction, interfere with sinus impulses, thus simulating a second-degree, 2:I, sinoatrial block.

The existence of concealed AV junctional extrasystoles was first suggested by Langendorf and Mehlman in 1947 and later in other reports (Langendorf, 1958; Need and Fisch, 1962; Langendorf and Pick, 1966; Friedberg, 1969; Schamroth and Surawicz, I97I) in order to explain the sudden occurrence, in particular cases, of PR interval prolongation or of nonconducted $P$ waves.

The presence of concealed beats was suggested because the onset or accentuation of AV blocks, in other parts of the electrocardiograms, were seen to be caused by manifest preceding AV junctional extrasystoles. The refractoriness induced by these extrasystoles in the AV junction, in fact, hindered the conduction of subsequent sinus impulses to the ventricles. In such cases, the suggested presence of concealed beats whenever the conduction to the ventricles is hindered, logically attributes the same effects to the same cause, not to the fortuitous coexistence of different causal mechanisms.

In other instances (Schamroth and Surawicz, I971; Lindsay and Schamroth, 1973) the nature of some AV blocks was dependent upon their occurring only concomitantly with nonmanifest $\mathrm{AV}$ junctional parasystolic discharges.

Other workers, recording the His bundle potentials, have shown the existence, in similar cases, of His bundle extrasystoles (Rosen, Rahimtoola, and Gunnar, 1970; Narula, 1973) or have experimentally reproduced (Damato, Lau, and Bobb, 1971) phenomena which are analogous to those in the clinical tracings.

In a case observed by us, concealed AV junctional extrasystoles led, in our opinion, to the failure of inscription of sinus $P$ waves in the electrocardiogram and not to pseudo AV blocks.

\section{Case report}

The Figure shows an electrocardiogram (aVL) recorded in a 60-year-old hypertensive female patient. Sinus rhythm is present with $R R$ intervals of about $81 .{ }^{1}$

The third ventricular complex is followed by a long PP interval of 154. Towards the end of the Figure, the eighth ventricular complex is followed by an AV junctional extrasystole, apparently with (Scherf and Cohen, 1964) simultaneous activation of atria and ventricles, with a compensatory pause, both included in a PP interval measuring 156, almost the same length as the long PP interval at the beginning of the Figure.

Phenomena such as those described have been observed several times in the patient.

\section{Discussion}

The long PP intervals without manifest extrasystoles, a little less than double the normal PP intervals in our case, seem to express a 2 : 1 seconddegree sinoatrial block (with sinus arrhythmia or concomitant first-degree sinoatrial block: Schamroth, 1967).

In other parts of the tracing, however, similar prolongations of the PP interval are evidently caused by the presence of extrasystoles. It is our opinion, therefore, in view of the two kinds of lengthening, and taking into account the observations referred to previously, that all the long PP intervals in our case are caused by the presence of an AV junctional extrasystole, manifest or concealed, followed by a compensatory pause and not, in some parts of the tracing, by a second-degree 2 : I sinoatrial block. We believe that the extrasystoles prevent sinus activity from being manifest. This can only take place if we assume that the extrasystolic impulses, travelling backwards through the right atrium, reach the sinoatrial junction and interfere with the sinus impulses (depolarization of the sinus node does not occur because, if this took place, owing to the resetting of the rhythm, the $P$ waves at the end of the

1 All time intervals are expressed in hundredths of a second. 


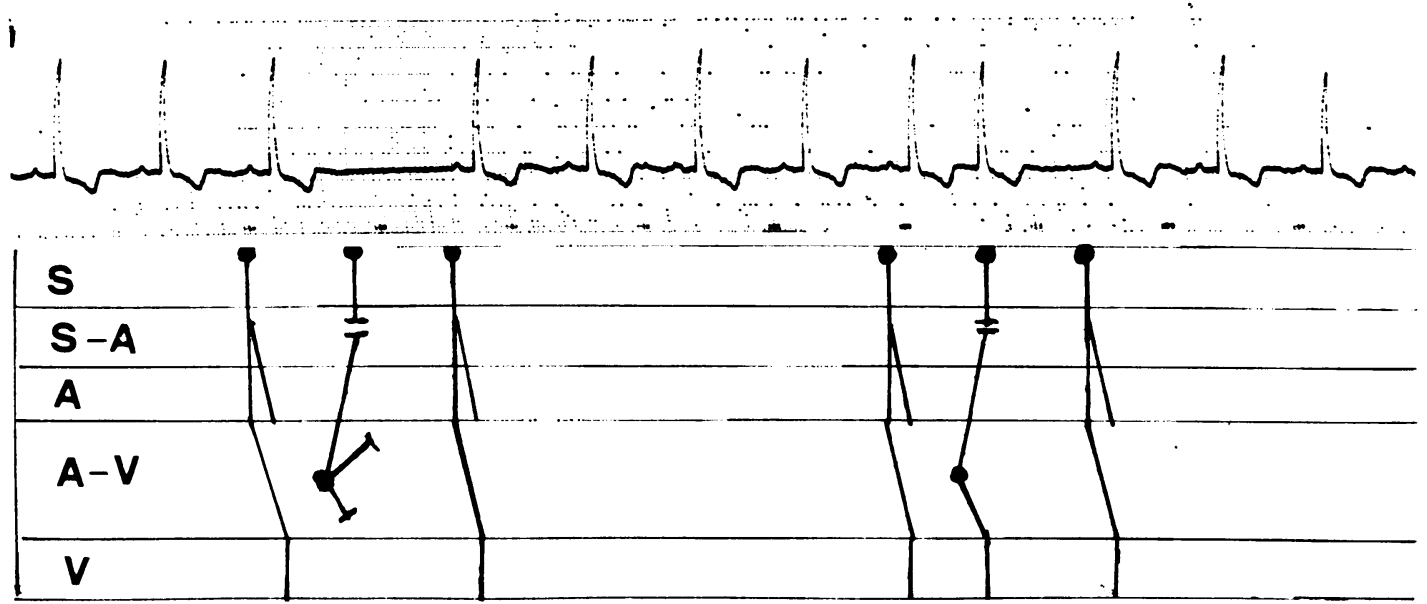

FI Diagram (according to Bellet and Fedlicka, 1969), illustrating the conduction of sinus impulses. There is no indication of the conduction of the impulses of the manifest extrasystoles to the non-specialized atrial myocardium (see text). $S=$ sinus node; $S A=$ sinoatrial junction; $A=$ atrium; $A V=A V$ junction; $V=$ ventricles.

long PP intervals would appear before they were expected.)

On the other hand, the extrasystolic impulses do not give rise to manifest retrograde $P$ waves. The latter could be lost in the QRS in the case of manifest extrasystoles and, using conventional electrocardiography, we would be unable to detect possible retrograde atrial activation. But, more important, the impulses of the concealed extrasystoles obviously do not produce such activation. We think that, in the course of these extrasystoles, the conduction of the impulses, blocked in the direction of the ventricles on one side, and blocked in the direction of the plain atrial myocardium on the other, occurs in concealed form and retrograde manner, from the atrioventricular junction to the sinoatrial junction along the preferential conduction pathways of the atria, the internodal tracts (James, 1963). These can be traversed backwards both in physiological (Sherf and James, 1969) and in pathological (Cosby and Bilitch, 1972) conditions.

Except for the inverted direction of the impulse and failure to reach the sinus node, the pathophysiological mechanism in this case is that which allows sinoventricular conduction to occur. This conduction, which leads to the activation by sinus impulses of the AV junction and ventricles, independently of the failed or delayed atrial activation, has already been suggested by Keith and Flack (1907) and later experimentally induced by potassium administration (Vassalle et al., I964; Vassalle and Hoffman, 1965; Wagner et al., 1966).
In clinical electrocardiography, disturbances in sinoatrial and sinoventricular conduction may combine in a different manner (see diagrams of Bellet and Jedlicka, 1969), and sinoventricular conduction has been taken into consideration as a probable explanation for the single electrocardiographic findings, both during hyperkalaemia (Bellet, 1963; Schamroth, 197I) and independently of the latter (during atrial arrest occurring in myocardial infarction: Jacobson, 1972).

The hypothesis could be advanced that in the present case among the repercussions of hypertension on the heart (the $\mathrm{ST}$ and T changes should also be seen) a probably hypoxic disturbance has determined a pronounced lengthening of the absolute and/or relative refractory period of the non-specialized atrial myocardium; the latter, in any case, is not excited by the impulses of the concealed extrasystoles. Instead the conduction pathways in the atria are less, or not at all, involved, and the extrasystolic impulses can travel along these pathways.

Instead we rule out the possibility that in our case the extrasystoles are of sinus origin, with the conduction to the atria either blocked or not detected. Even in this case the rhythm would reset on the extrasystole and the long PP interval would be shorter than it actually is.

As far as we know, this is the first case hitherto described in which concealed AV junctional extrasystoles have conditioned the conduction of subsequent sinus impulses operating outside the AV junction. This occurs because of the particular 
manner in which, as we have shown, the ectopic impulses have been conducted.

\section{References}

Bellet, S. (1963). Clinical Disorders of the Heart Beat, Fig. 42-2 and $13-5$. Lea and Febiger, Philadelphia.

Bellet, S., and Jedlicka, J. (I969). Sinoventricular conduction and its relation to sinoatrial conduction. American fournal of Cardiology, 24, 831.

Cosby, R. S., and Bilitch, M. (1972). Heart Block, pp. 25-27. McGraw-Hill, New York.

Damato, A. N., Lau, S. H., and Bobb, G. (I97I). Cardiac arrhythmias simulated by concealed bundle of His extrasystoles in the dog. Circulation Research, 28, 316.

Friedberg, H. D. (1969). Concealed extrasystoles. American fournal of Cardiology, 24, 283.

Jacobson, L. B. (1972). Sinoventricular conduction during atrial arrest. Fournal of Electrocardiology, 5, 385 .

James, T. N. (1963). The connecting pathways between the sinus node and AV node and between the right and left atrium in the human heart. American Heart fournal, 66, 498.

Keith, A., and Flack, M. (1907). The form and nature of the muscular connections between the primary divisions of the vertebrate heart. Fournal of Anatomy and Physiology, 4r, I72.

Langendorf, R. (1958). Alternation of A-V conduction time. American Heart fournal, 55, 181.

Langendorf, R., and Mehlman, J. S. (1947). Block (nonconducted) A-V nodal premature systoles imitating first and second degree A-V block. American Heart fournal, 34, 500.

Langendorf, R., and Pick, A. (1966). Concealed conduction in the A-V junction. In Mechanisms and Therapy of Cardiac Arrhythmias, p. 395. Ed. by L. S. Dreifus, W. Likoff, and J. H. Moyer. Grune and Stratton, New York and London.

Lindsay, A. E., and Schamroth, L. (1973). Atrioventricular junctional parasystole with concealed conduction simu- lating second degree atrioventricular block. American Fournal of Cardiology, 31, 397.

Narula, O. S. (1973). Conduction disorders in the AV transmission system. In Cardiac Arrhythmias, p. 259. Ed. by L. S. Dreifus and W. Likoff. Grune and Stratton, New York and London.

Need, R. L., and Fisch, C. (1962). Heart block resulting from concealed discharge of the atrioventricular node. American Fournal of Cardiology, 10, 138.

Rosen, K. M., Rahimtoola, S. H., and Gunnar, R. M. (1970). Pseudo A-V block secondary to premature non-propagated His bundle depolarizations. Documentation by His bundle electrocardiography. Circulation, 42, 367.

Schamroth, L. (1967). The diagnosis of first-degree sinoatrial block. South African Medical fournal, 41, 684 .

Schamroth, L. (197I). The Disorders of Cardiac Rhythm, case 137, p. 504. Blackwell Scientific Publications, Oxford and Edinburgh.

Schamroth, L., and Surawicz, B. (1971). Concealed interpolated A-V junctional extrasystoles and A-V junctional parasystole. American fournal of Cardiology, 27, 703.

Scherf, D., and Cohen, J. (1964). The Atrioventricular Node and Selected Cardiac Arrhythmias, p. 159. Grune and Stratton, New York and London.

Sherf, L., and James, T. N. (1969). A new electrocardiographic concept: synchronized sinoventricular conduction. Diseases of the Chest, 55, 127.

Vassalle, M., Greenspan, K., Jomain, S., and Hoffman, B. F. (1964). Effects of potassium on automaticity and conduction of canine hearts. American fournal of Physiology, 207, 334 .

Vassalle, M., and Hoffman, B. F. (1965). The spread of sinus activation during potassium administration. Circulation Research, 17, 285.

Wagner, M. L., Lazzara, R., Weiss, R. M., and Hoffman, B. F. (1966). Specialized conducting fibers in the interatrial band. Circulation Research, 18, 502.

Requests for reprints to Dr. A. Brat, Corso Matteotti, 43, 5Ior6 Montecatini Terme, Italy. 